\title{
Cardiac manifestation of the huge pulmonary mass simulating ST-elevation myocardial infarction
}

\author{
Nancy Wassef*1, Sarah Dorrington ${ }^{2}$, George Pulikal ${ }^{2}$ \\ ${ }^{1}$ Kettering General Hospital, Kettering, Northamptonshire, United Kingdom \\ ${ }^{2}$ Birmingham Heartlands Hospital, Birmingham, West Midlands, United Kingdom
}

Received: March 21, 2016

DOI: $10.5430 /$ crim.v3n4p84
Accepted: October 9, 2016

Online Published: October 12, 2016

\begin{abstract}
A 77-year-old Caucasian female presented with central chest pain and an electrocardiogram showing anterior and inferior ST segment elevation. The patient had discrepancy of the blood pressure measurement and unequal radial pulses of the upper limbs. Urgent CT thorax and aorta showed no evidence of aortic dissection, but it showed a large mass in the left lung lower lobe, which involved the adjacent structures including the left ventricular. The patient refused to have a bronchoscopy or any further investigations and was discharged to the community with palliative care support.
\end{abstract}

Key Words: Myocardial infarction, Cardiac tumours, Malignant metastases

\section{INTRODUCTION}

Whilst ST segment elevation on electrocardiogram (ECG) in association with chest pain and raised cardiac troponin is often associated with acute myocardial infarction, it is not always caused by coronary artery disease (CAD). We present a case where the patient presented with chest pain and an electrocardiogram showing ST elevation myocardial infarction (STEMI), in which the underlying aetiology was metastatic infiltration of the myocardium.

\section{Case presentation}

A 77-year-old Caucasian female presented to the emergency department with central chest pain of a severe intensity with numbness in her left arm. Her ECG showed ST segment elevation and she was suspected of having an antero-inferior STEMI. She had no risk factors for CAD except for being an ex-smoker and had chronic obstructive pulmonary disease. The patient had a previous history of cancer breast, which was treated with lumpectomy, chemotherapy and local radiotherapy, thirty years before admission.

On examination her left hand was cool to touch in comparison to all other limbs, with unequal radial pulse volumes and discrepancy in blood pressure (BP) measurements of the upper limbs, with right arm BP of $121 / 57 \mathrm{mmHg}$, and left arm BP of $60 / 39 \mathrm{mmHg}$, which were persistent despite repeated recordings. The patient had no neurological deficit on full neurological examination. On further questioning she gave an un-quantified history of weight loss over several months with non-productive cough.

ECG demonstrated ST elevation in V2-6, II, III and aVF (see Figure 1). Initially the high sensitive troponin I (Abbott hs-Troponin I) was 5,449 $\mathrm{ng} / \mathrm{L}(<26)$ and the patient was found to have microcytic anaemia with a haemoglobin of $81 \mathrm{~g} / \mathrm{L}$ and raised white blood cells of $20 \times 10^{9} / \mathrm{L}$ and CRP $93 \mathrm{mg} / \mathrm{L}$ with normal renal and liver function tests.

\footnotetext{
*Correspondence: Nancy Wassef; Email: nancy.wassef@gmail.com; Address: Kettering General Hospital, Kettering, Northamptonshire, United Kingdom.
} 
The chest X-ray showed left lower zone consolidation patch (see Figure 2). Urgent CT thorax and CT aortic angiography showed no evidence of aortic dissection with lung emphysematous changes. However, the CT showed a large mass in the left lung lower lobe measuring $9 \mathrm{~cm} \times 9 \mathrm{~cm} \times 8 \mathrm{~cm}$ involving the adjacent pleura, diaphragm and pericardium with contralateral mediastinal lymphadenopathy. There was no clear fat plane between the mass and the left ventricular heart muscle denoting involvement of the heart muscle. This was highly suggestive of T3, N3, M0 primary lung tumour (see Figure 3). In addition there was a thrombus causing partial occlusion of the left Subclavian artery, for which she was started on anticoagulation therapy (see Figure 4). The patient declined echocardiography and coronary angiography, which would have been helpful in delineating the presence regional wall motion abnormality and the angiogram would have excluded the presence of associated coronary artery disease. The respiratory multi-disciplinary meeting discussion was in agreement with palliative management, given the large mass and the late stage of malignancy. The patient declined bronchoscopy and further investigations of her lung mass and was discharged to the community with palliative care support.

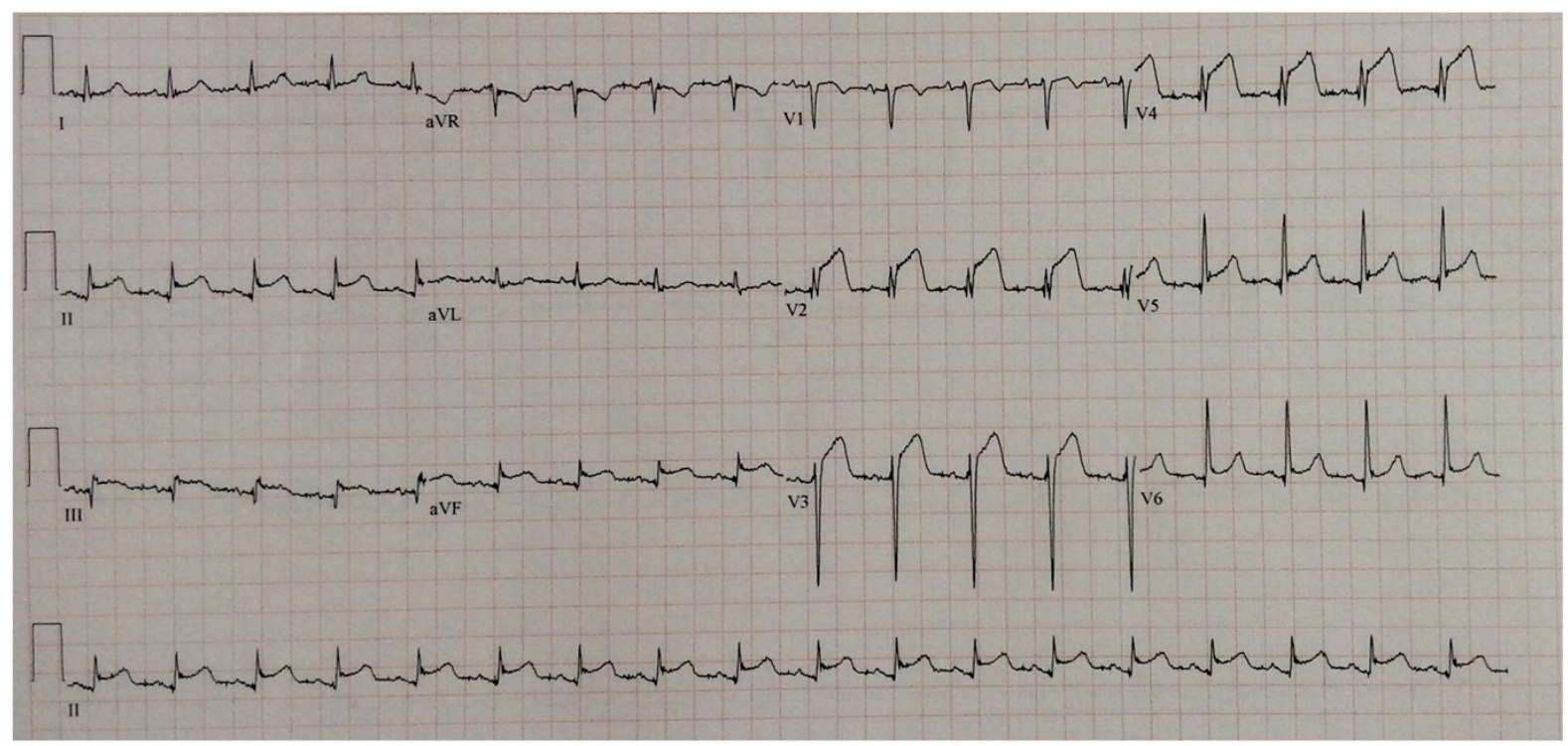

Figure 1. ECG showing ST elevation of the anterior and inferior leads

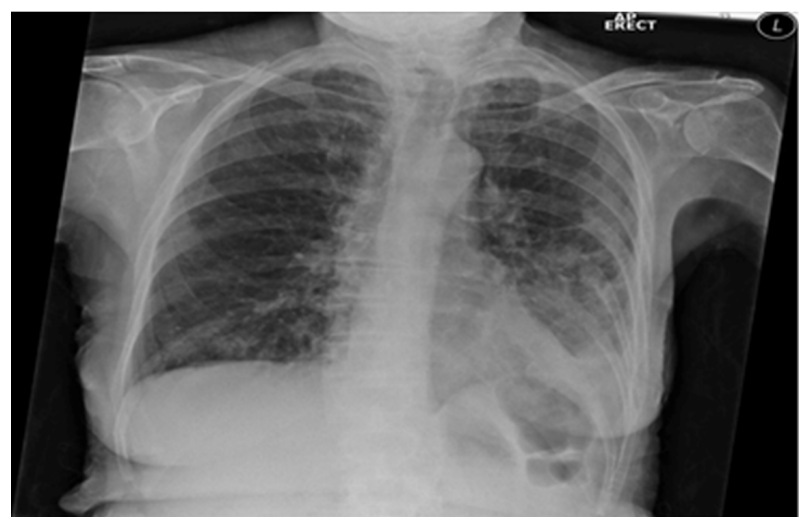

Figure 2. Chest X-ray showing left lower lung consolidation patch

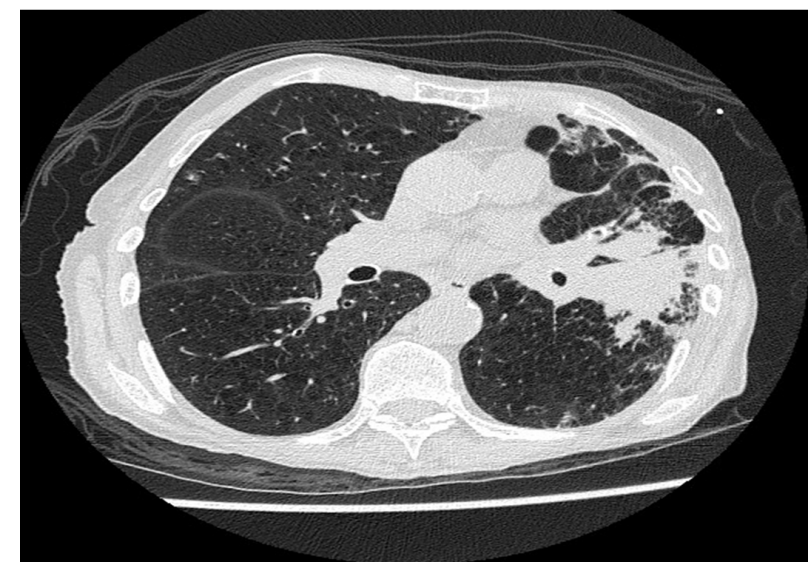

Figure 3. CT thorax showing a large left lung space occupying infiltrating lesion 


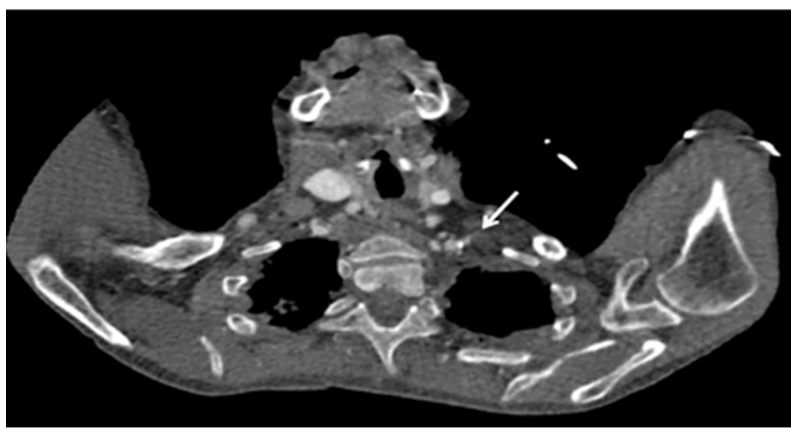

Figure 4. CT chest showing partial obstruction of left Subclavian artery (arrow)

\section{Discussion}

Primary cardiac tumours are rare with a frequency of $0.001 \%$ $0.03 \%$, however cardiac metastases are much more common with an estimated frequency of 100 to 1,000 times more than cardiac primaries. ${ }^{[1]}$ Although it is considered to be uncommon, autopsy studies have demonstrated that up to $20 \%$ of patients with a known diagnosis of malignancy have cardiac metastases. ${ }^{[2]}$ The most common underlying malignancies with secondary cardiac involvement include carcinoma of the lung, breast, oesophagus, stomach, kidneys as well as melanoma, lymphoma and leukaemia. The primary lung carcinomas, account for around one third of cardiac metastases. $^{[1,3]}$

The most common manifestations of cardiac tumours are asymptomatic ECG changes, arrhythmias and congestive heart failure. Often, tumours can present with pericardial ef- fusions with or without tamponade. Others may present with constitutional or systemic symptoms. Ischaemic changes of the ECG are common manifestations with cardiac metastases, with a very small minority present with ST segment elevation as seen in our case. ${ }^{[1,4]}$

There are few previously described cases, in which cardiac metastases from another organ mimics an acute coronary syndrome. Primary tumours previously demonstrated to show a similar presentation include head and neck, kidney, carcinoid, melanoma, thyroid and oesophageal tumours, and in patients with a known diagnosis of lung cancer. ${ }^{[5]}$

This case highlights the importance of raising clinical awareness of cardiac metastases, which can be presenting as acute coronary syndrome.

\section{Learning outcome}

Although ST elevation on ECG with chest pain and raised cardiac enzymes is most commonly associated with acute myocardial infarction, CAD is not always the aetiology.

Primary cardiac tumours are rare, but cardiac metastases are much more common, with estimated magnitudes ranging from 100 to 1,000 times more frequent than cardiac primaries. $^{[1]}$

Autopsy studies have demonstrated that up to $20 \%$ of patients with diagnosed malignancy have cardiac metastases. ${ }^{[2]}$

CONFlicts OF InTEREST Disclosure

The authors have declared no conflicts of interest.

\section{REFERENCES}

[1] Bruce CJ. Cardiac Tumours: diagnosis and management. Heart. 2011; 97: 151-160. PMid:21163893 http://dx.doi.org/10.1136/h rt. 2009.186320

[2] Hiremath R, Aishwarya KC, Noronha GP, et al. Metastatic Cardiac Tumor from Bronchogenic Carcinoma via Pulmonary Vein. J Clin Diagn Res. 2013; 7(11): 2600-2601. PMid:24392417

[3] Tamura A, Matsubaraet O, Yoshimura N, et al. Cardiac metastasis of lung cancer. A study of metastatic pathways and clinical manifestations. Cancer. 1992; 70(2): 437-42. http://dx.doi.org/10.1002/1097-0142(19920715)70: 2<437: :AID-CNCR2820700211>3.0.CO;2-L

[4] Vlachostergios PJ, Daliani DD, Papandreou CN. Basic Concepts in Metastatic Cardiac Disease. Cardiol Res. 2012; 3(2): 47-48.

[5] Daher IN, Luh, JY, Duarte AG, et al. Squamous cell lung cancer simulating an acute myocardial infarction. Chest. 2003; 123(1): 304-6. PMid:12527639 http://dx.doi.org/10.1378/chest. 1 23.1.304 